\title{
Bone disease in pediatric chronic kidney disease
}

\author{
Katherine Wesseling-Perry \\ Department of Pediatrics, David Geffen School of Medicine at UCLA, A2-383 MDCC, 650 Charles \\ Young Drive, Los Angeles, CA 90095, USA kwesseling@mednet.ucla.edu
}

\begin{abstract}
Children with long-standing chronic kidney disease (CKD) display clinical symptoms of bone disease, including bony deformities and fractures, which contribute to long-standing disability. Abnormalities in skeletal mineralization occur in a substantial proportion of this population and may contribute to chronic morbidity. Underscoring the potential contribution of parameters other than bone turnover to bone disease in CKD, a new definition for renal osteodystrophy (ROD), emphasizing the assessment of three key histologic descriptors, i.e., bone turnover (T), mineralization (M), and volume (V) (TMV), has been recommended in the assessment of all patients with CKD. Although bone biopsy is the only available method for assessing all three recommended areas of bone histology, this invasive procedure is not routinely used in any clinical setting; thus, a true understanding of the prevalence of abnormal turnover, defective mineralization, and altered bone volume throughout the course of CKD is limited. Recent data, however, have shed light on the progression of renal ROD throughout the course of CKD, including its early stages, as well as on the alterations in cell biology that accompany ROD.
\end{abstract}

\section{Keywords}

CKD-MBD; Renal osteodystrophy; Parathyroid hormone; Fibroblast growth factor 23

\section{Introduction}

Chronic kidney disease (CKD) causes disordered regulation of mineral metabolism with subsequent alterations in skeletal and cardiovascular biology. Together, these manifestations are termed the chronic kidney disease mineral and bone disorder (CKD-MBD) [1, 2]. Renal osteodystrophy (ROD), a disorder of bone remodeling, is one element of the CKD-MBD which is quantifiable by bone histomorphometry. Although ROD has traditionally been classified according to lesions of bone turnover, which are effectively controlled with phosphate binder and vitamin D sterol therapy [3, 4], children with long-standing CKD continue to display clinical symptoms of bone disease, including bony deformities and fractures which contribute to long-standing disability [5,6]. Abnormalities in skeletal mineralization occur in a substantial proportion of pediatric patients with CKD [7] and may contribute to the increased fracture rates, bony deformities, poor linear growth, and chronic bone pain that persist despite adequate control of secondary hyperparathyroidism [4]. Underscoring the potential contribution of parameters other than bone turnover to clinical symptoms of bone disease, a new definition of ROD, emphasizing the assessment of three key histologic descriptors, namely, bone turnover $(\mathrm{T})$, mineralization $(\mathrm{M})$, and volume $(\mathrm{V})$ (TMV), has been recommended in all patients with CKD [1, 2]. Although the bone biopsy is the only available method for assessing all three recommended areas of bone histology [8],

(C) IPNA 2012

Correspondence to: Katherine Wesseling-Perry. 
this invasive procedure is not routinely used in any clinical setting, and very few laboratories are equipped to perform bone histomorphometric analysis. Moreover, more readily accessible tools, including bone densitometry, have not proven predictive of bone disease or useful in the management of patients with CKD and are not generally recommended for the assessment of ROD [9]. Thus, a true understanding of the nature of ROD throughout the course of CKD is limited, and the true pathogenesis of ROD, particularly in its early stages, is incompletely understood. However, recent data have shed light on the progression of ROD throughout the course of CKD, including its early stages and on the alterations in cell biology that accompany ROD.

\section{Pathogenesis of secondary hyperparathyroidism and the predictive value of parathyroid hormone}

The decline in circulating levels of $1,25(\mathrm{OH})_{2}$ vitamin $\mathrm{D}$ that occurs in early CKD has traditionally been attributed to a decrease in functional renal tissue. However, the concept of declining renal mass as the primary determinant of reduced $1,25(\mathrm{OH})_{2}$ vitamin D levels in early CKD changed in 2005 when Gutierrez et al. described a significantly higher prevalence of $1,25(\mathrm{OH})_{2}$ vitamin D deficiency than of anemia (i.e., erythropoietin deficiency) in adult patients with early CKD [10]. Earlier studies had demonstrated that levels of fibroblast growth factor 23 (FGF23), a skeletal hormone which, in conjunction with its co-receptor, Klotho, binds to various fibroblast growth factor receptors (FGFRs) to induce phosphaturia and suppress calcitriol production [11, 12], were increased in patients with various degrees of renal dysfunction [13]. Together, these data suggested that suppression of renal $1 \mathrm{a}$-hydroxylase, rather than the loss of renal mass (which would be expected to affect renal 1a-hydroxylase and erythropoietin to a similar degree), results in decreased values of $1,25(\mathrm{OH})_{2}$ vitamin $\mathrm{D}$, particularly in early stages of $\mathrm{CKD}$, and that this suppression may be mediated by increasing circulating FGF23 levels. Although controversy exists as to the etiology of these increased values in early CKD, with some studies suggesting a role for possibly intermittent increases in enteral phosphate burden and others suggesting stimulation by increases in circulating parathyroid hormone (PTH) $[14,15]$, current data demonstrate that FGF23 levels rise early in the course of CKD. Indeed, circulating FGF23 levels are increased in 30-40 \% of adults with an estimated glomerular filtration rate (GFR) of 70-90 ml/min/1.73 $\mathrm{m}^{2}$, while parathyroid hormone (PTH) concentrations are above the normal range in only $10 \%$ of these same individuals [16]. Several studies in children are consistent with these data from the adult population [17-21]; thus, it appears that increases in FGF23 may be the first detectable biochemical evidence for an abnormal regulation of mineral ion homeostasis in early CKD, leading to the early decline in $1,25(\mathrm{OH})_{2}$ vitamin D levels (Fig. 1).

Following increases in FGF23, a decline in $1,25(\mathrm{OH})_{2}$ vitamin D levels leads both to impaired intestinal calcium absorption as well as to increased serum PTH values [22]. Elevated PTH levels maintain normocalcemia in the face of impaired intestinal calcium absorption by increasing calcium release from bone. Bone resorption, however, leads to an increase in the amount of phosphate that must be excreted by a declining number of functional nephrons. When renal function becomes severely impaired, phosphate levels rise, further suppressing renal 1a-hydroxylase activity and stimulating PTH [3]. Thus, in late stages of CKD, hypocalcemia, hyperphosphatemia, and low circulating $1,25(\mathrm{OH})_{2}$ vitamin D concentrations all contribute to the development of secondary hyperparathyroidism.

Secondary hyperparathyroidism has long been the primary target of therapy in patients with CKD as persistently elevated levels of PTH stimulate osteoblastic activity and increase bone turnover [23], with clinical consequences of poor growth, bony deformities, and fractures [24]. However, skeletal resistance to the actions of PTH develops as CKD progresses, 
resulting in the need for higher PTH levels to maintain normal rates of bone formation [1, 2, 8]. The pathogenesis of skeletal PTH resistance is incompletely understood, but several factors contribute, including, but probably not limited to, the accumulation of biologically active PTH fragments [25, 26] and downregulation of the PTH receptor [27]. Although the actions of many different fragments of the PTH molecule are still uncharacterized, in vitro and in vivo experimental data indicate that one or more amino-terminally truncated $\mathrm{PTH}(1-$ 84) fragments antagonize the calcemic actions of $\mathrm{PTH}(1-84)$ and diminish bone cell activity, thereby modulating bone metabolism. Indeed, synthetic PTH(7-84), which appears to be similar to naturally occurring circulating amino-terminally truncated PTH fragments [28], inhibits the formation of tartrate resistant acid phosphatase (TRAP)-positive boneresorbing cells in vitro [27] and inhibits bone formation in vivo [29], while dialysis patients with hyperparathyroid bone disease due to increased levels of PTH(1-84) have increased circulating levels of PTH(7-84) and are resistant to the calcemic actions of PTH(1-34) [25]. These data suggest that at least some of the different carboxyl-terminal PTH fragments have biological activity and may play a role in the skeletal resistance to the full-length PTH molecule.

Shortcomings of the first generation immunometric assays (IMA) for measuring PTH (1st PTH-IMA) have been highlighted over the years and may also contribute to discrepancies between PTH measurement and bone formation rate in patients with CKD. Indeed, 1st PTHIMAs detect not only the intact hormone, but also PTH fragments truncated at the aminoterminus [30-32]; thus, most detection antibodies, which are usually directed against epitopes within the amino-terminus of the hormone, detect not only PTH(1-84), but also one or several amino-truncated fragments of the PTH molecule [32]. Although second generation immunometric PTH assays (2nd PTH-IMAs) do not detect these large aminoterminally truncated PTH fragments [33] and were initially thought to be better predictors of bone turnover [34], subsequent investigations failed to confirm their superiority over 1st PTH-IMAs [35, 36]. Moreover, it is now apparent that values of PTH vary between assay manufacturers; indeed, Joly et al. reported that the diagnosis of hyperparathyroidism could have changed in 11 of 34 patients had different assays been utilized [37]. As a result, any interpretation of PTH values is difficult and affected by the assay used; significant controversy exists regarding the optimal target levels of PTH in children with all CKD stages. Even in the dialysis population, in whom the majority of bone biopsies worldwide have been performed, recommendations vary widely. Current recommendations by the National Kidney Foundation suggest that levels be maintained between 200 and 300 pg/ml [8], the European Pediatric Dialysis Group suggests that values between two- and threefold the upper limit are optimal in dialyzed children [38], and a much broader range-between two- and ninefold the range for normal individuals-is recommended by the Kidney Disease: Improving Global Outcomes (KDIGO) foundation for patients treated with maintenance dialysis [2]. The data in the pre-dialysis CKD population are very limited, with only one existing study describing PTH values and bone histology in pediatric patients with early kidney dysfunction [21]; thus, further studies are critically needed to define optimal target PTH ranges throughout the course of CKD.

\section{Bone disease across the spectrum of CKD}

As stated by the Kidney Disease Outcomes Quality Initiative (KDOQI) guidelines for bone disease in children with CKD, "The most accurate diagnostic test for determining the type of bone disease associated with CKD is iliac crest bone biopsy with double tetracycline labeling and bone histomorphometric analysis (EVIDENCE)" [8]. At the time that these guidelines were developed, a paucity of bone biopsy data existed in the pre-dialysis CKD population, thus all recommendations regarding the management of bone disease in early CKD were based exclusively on opinion. Since publication of the KDOQI guidelines, 
several important advances have been made in the field of bone disease in the pediatric CKD population. The first was the redefinition, by the KDIGO working group, of ROD to include measurements of skeletal mineralization and bone volume, in addition to the traditional parameters of bone turnover, in the assessment of bone histology [1]. Following this statement, a startlingly high prevalence of mineralization defects was described in pediatric dialysis patients [7, 39]. Subsequently, the prevalence of TMV abnormalities has been described in the pediatric CKD population, including patients with very early (stage 2) CKD [21]. Finally, recent data describing changes in osteocyte physiology early in the course of CKD $[40,41]$ have resulted in an increased understanding of the pathophysiology of ROD, including the changes in bone metabolism that occur before the development of secondary hyperparathyroidism.

\section{Spectrum of pediatric ROD in end stage kidney disease}

Lesions of ROD have traditionally been defined by changes in bone turnover, with lesions of high bone turnover presenting the most common defect in the pediatric dialysis population [42]. However, in 2010, Bakkaloglu et al. [7] demonstrated a high prevalence of mineralization defects in a cross-section of 161 dialysis patients after at least 4 weeks of washout from active vitamin D sterol therapy prior to bone biopsy. While high bone turnover was found to be the predominant skeletal lesion, with $57 \%$ of the subjects displaying increased rates of bone formation and only $4 \%$ displayed lesions of low bone turnover, abnormal mineralization, defined by a concurrent increase in osteoid volume and osteoid maturation time, was found in a high percentage of the population, irrespective of the underlying bone formation rate. Indeed, $48 \%$ of all subjects, including $58 \%$ of those with high bone turnover, $38 \%$ of those with normal bone turnover, and $29 \%$ of those with low bone turnover, displayed abnormalities in skeletal mineralization [7]. Although FGF23 - the levels of which were found to correlate with skeletal mineralization in subsequent studies [40, 43] — was not evaluated in this analysis, serum PTH and alkaline phosphatase values were both directly related to bone formation rate while defective mineralization was associated with higher serum PTH and lower serum calcium levels. These data suggest that no single biochemical marker is able to provide a complete assessment of ROD but that a combination of biochemical parameters, including PTH, alkaline phosphatase, and calcium, might allow for improved assessment of turnover and mineralization abnormalities in pediatric patients treated with maintenance dialysis. The value of such a treatment strategy, as well as the potential role of FGF23 and other markers, such as bone specific alkaline phosphates, collagen cross-links, and osteocalcin, in the assessment in the treatment of ROD will need to be confirmed by prospective randomized studies.

The high prevalence of mineralization defects in the pediatric dialysis population was confirmed in a subsequent clinical trial by Wesseling-Perry et al. [39] in which, at baseline, over $80 \%$ of subjects, all of whom had high bone turnover at baseline, displayed histomorphometric evidence of defective mineralization. In this trial, despite the majority of patients with active vitamin $\mathrm{D}$ sterol and phosphate binder therapy showing a reduction in PTH values and normalization of bone turnover, skeletal mineralization remained abnormal [39]. The reasons behind this persistent defect in skeletal mineralization remain unknown, but animal data have recently implicated active vitamin $\mathrm{D}$ sterols in potentiating the mineralization defect. Indeed, osteoblastic vitamin D receptor (VDR) signaling appears to directly stimulate the transcription of genes encoding mineralization inhibitors, such as pyrophosphate, likely through increased expression of ectonucleotide pyrophosphatase/ phosphodiesterases 1 and 3 (Enpp1 and Enpp3) and ankalsosis (Ank) and through concomitant suppression of tissue non-specific alkaline phosphatase (TNAP) expression [44]. Alternatively, deficiency of $25(\mathrm{OH})$ vitamin D [45] or alterations in osteocytic FGF23 expression may also contribute to this persistent defect [40]. 


\section{Spectrum of ROD: pre-dialysis CKD}

Until recently, as highlighted by the KDOQI guidelines, a paucity of data existed on the prevalence and characteristics of bone disease in the pre-dialysis CKD population [8]. In 2012, however, one study evaluated the spectrum of ROD in pediatric pre-dialysis CKD patients [21]. In this study of 52 patients with CKD stages 2-4, bone turnover was normal in all subjects with CKD stage 2 and in the majority of those with CKD stage 3 . Bone formation was increased, however, in $29 \%$ of patients with CKD stage 4 (Fig. 2). It is interesting to note that only four subjects from the entire cohort displayed evidence of adynamic bone disease. All four of these individuals had either CKD stage 2 ( $n=2$, neither of whom received phosphate binders or vitamin D sterols) or stage 3 ( $n=2$, both of whom received oral calcitriol).

In contrast to the rather late increases in bone turnover, abnormalities in skeletal mineralization were present as early as CKD stage 2 (Fig. 2). Excess osteoid accumulation, defined as increased osteoid volume/bone volume, was observed in $43 \%$ of subjects with CKD stage 2 and in $86 \%$ of patients with CKD stage $4 / 5$. Similarly, a prolongation in osteoid maturation time was observed in $43 \%$ of subjects with stage $2 \mathrm{CKD}, 79 \%$ of those with CKD stage 3 , and $79 \%$ of those with CKD stage 4/5. In order to separate a true mineralization defect from hyperosteoidosis resulting from increased osteoblastic activity, "defective mineralization" was defined as an increase in osteoid volume/bone volume in combination with a prolongation in osteoid maturation time. Using this definition, $29 \%$ of all subjects with stage $2 \mathrm{CKD}, 42 \%$ of those with stage $3 \mathrm{CKD}$, and $79 \%$ of subjects with stage 4/5 CKD displayed evidence of a mineralization defect. Although PTH levels were in the normal range in the majority of subjects with CKD stages 2 and 3, circulating FGF23 values were overtly elevated in all CKD stages. Overall, the majority of subjects, irrespective of CKD stage, displayed either normal or increased bone volume, and only two subjects (one in CKD stage 1 and 1 in CKD stage 2) had evidence of low bone volume.

\section{Osteocyte dysfunction in early CKD: effect on ROD}

Recent data from animals and humans suggest that abnormalities in skeletal biology, specifically in osteocytic protein expression, occur very early in the course of CKD, before changes in PTH are apparent, and that they may be critical to the pathogenesis of abnormal bone turnover and mineralization in early CKD. Indeed, in 2004 Lund et al. [46] demonstrated that renal ablation in mice resulted in low bone turnover if circulating levels of calcium, phosphate, $1,25(\mathrm{OH})_{2}$ vitamin $\mathrm{D}$, and PTH were kept constant, suggesting that some changes in bone turnover, particularly in early CKD, are independent of measurable changes in mineral ion homeostasis. Subsequently, Sabbagh et al. [41] demonstrated similar findings in $J c k$ mice in whom increased osteocytic sclerostin expression was related to changes in bone turnover with progressive kidney disease. Sclerostin is an inhibitor of Wnt signaling-mediated bone turnover; thus, increases in its expression result in the suppression of bone formation and the development of adynamic bone early in the course of kidney disease [41]. PTH, however, suppresses sclerostin expression [47] and, as moderate to severe CKD develops, rising PTH levels inhibit skeletal sclerostin expression, allowing bone formation rates to increase [41].

The abnormalities in skeletal mineralization that occur in early CKD also appear to be linked to changes in osteocyte biology. In 2009, Pereira et al. [40] reported that osteocytic protein expression is altered early in the course of CKD and that the expression of some of these proteins may be linked to the abnormalities in skeletal mineralization that are apparent in early pediatric CKD. Indeed, skeletal expression FGF23 is already markedly upregulated in osteocytes in very early CKD [40], occurring as early as stage 2 CKD (Fig. 3), at a time 
when serum PTH, vitamin D, calcium, and phosphorus concentrations are still within the normal range [22] but when circulating values of FGF23 are increased [16]. Increased plasma FGF23 levels may be secondary to defects in regulatory proteins, including the osteocytic protein dentin matrix protein 1 (DMP1) and ecto-nucleotide pyrophosphatase/ phosphodiesterase (ENPP1), as documented in patients with normal renal function who develop different forms of hypophosphatemic rickets [40, 48, 49]. These findings, which are consistent with those in animals lacking these two proteins $[48,50]$, have suggested that DMP1 and ENPP1 are negative regulators of FGF23 synthesis and secretion. However, the early increases in FGF23 observed in pediatric patients with CKD are associated with an increase, rather than a decrease, in osteocytic DMP1 expression [40] (Fig. 4). In the context of CKD, osteocytic expression of both FGF23 and DMP1 correlates with histomorphometric parameters of skeletal mineralization [40]. Thus, it appears that osteocytes, which are presumably the source of increased circulating FGF23 levels early in the course of CKD, are unable to generate sufficiently high levels of a biologically active DMP1 to suppress osteocytic FGF23 production; abnormalities in osteocyte function thus occur even with only mild decreases in kidney function. Moreover, the osteocyte, previously thought to be a relatively quiescent cell with a role limited to skeletal mechanosensation, is an endocrine cell, and the disruption of its normal biology triggers alterations in parathyroid gland biology, mineral metabolism, and skeletal mineralization in patients with all stages of CKD.

\section{Implications for therapy}

Circulating levels of FGF23 have been identified as an independent risk factor for mortality in adult CKD patients and in the general population at large [51-53], and short-term trials have demonstrated that treatment with either sevelamer- $\mathrm{HCl}$ or lanthanum carbonate may reduce elevated FGF23 levels, resulting in increased circulating $1,25(\mathrm{OH})_{2}$ vitamin D and decreased PTH values without altering serum phosphorus levels in normophosphatemic patients with CKD stages 3 and $4[54,55]$. Calcium-based phosphate binders, by contrast, have not proven effective in lowering FGF23 values [54], and animal data suggest that calcium may stimulate FGF23 expression [56]. Treatment with active vitamin D sterols has been linked with improved survival rates in large cohorts of dialysis patients [57, 58]; however, this form of therapy increases circulating FGF23 values [39] which have themselves been identified as an independent risk factor for cardiovascular disease and mortality in all stages of CKD [52, 53, 59]. While no prospective studies have yet been performed to assess the reason behind this paradox, active vitamin D sterol therapy is currently recommended in pre-dialysis CKD patients when PTH levels begin to rise [8], and further studies are needed to assess the systemic implications of these recommendations on morbidity and mortality in CKD. Indeed, the prevention of excessive intestinal phosphorus absorption with non-calcium-containing phosphate binders in early CKD, when serum phosphorus levels are in the normal range, may be of critical importance in preventing secondary hyperparathyroidism and preserving native renal $1,25(\mathrm{OH})_{2}$ vitamin $\mathrm{D}$ production while preventing a rise in FGF23 [54]. The direct association between FGF23 with height standard deviation score (SDS) and insulin-like growth factor 1 (IGF1) levels in children with CKD [17, 21] further complicates recommendations in the pediatric population as therapies aimed at lowering FGF23 levels in children may have adverse consequences on linear growth. Thus, further studies are needed to determine the long-term consequences of ROD therapies on bone biology, growth, and cardiovascular disease in children with CKD.

\section{Summary}

Defective skeletal mineralization is prevalent early in the course of pediatric CKD, prior to the development of abnormalities in bone turnover. These defects occur at a time when circulating levels of calcium, phosphorus, vitamin D, and PTH are within the normal range 
in the majority of patients and develop in conjunction with alterations in osteocyte biology, namely increased osteocytic FGF23 and DMP1 expression. Thus, osteocyte dysfunction, occurring early in the course of CKD, likely contributes to significant morbidity in this population. Current therapies aimed at the treatment of ROD may affect osteocyte function, and further studies are needed to determine the effects of these regimens on bone biology as well as to determine optimal target ranges for biomarkers.

\section{References}

1. Moe S, Drueke T, Cunningham J, Goodman W, Martin K, Olgaard K, Ott S, Sprague S, Lameire N, Eknoyan G. Definition, evaluation, and classification of renal osteodystrophy: a position statement from Kidney Disease: Improving Global Outcomes (KDIGO). Kidney Int. 2006; 69:1945-1953. [PubMed: 16641930]

2. Group KW. KDIGO clinical practice guideline for the diagnosis, evaluation, prevention, and treatment of chronic kidney disease-mineral and bone disorder (CKD-MBD). Kidney Int. 2009; 76:s1-s130.

3. Sherrard DJ, Hercz G, Pei Y, Maloney NA, Greenwood C, Manuel A, Saiphoo C, Fenton SS, Segre GV. The spectrum of bone disease in end-stage renal failure-an evolving disorder. Kidney Int. 1993; 43:436-442. [PubMed: 8441240]

4. Mahdavi H, Kuizon BD, Gales B, Wang HJ, Elashoff RM, Salusky IB. Sevelamer hydrochloride: an effective phosphate binder in dialyzed children. Pediatr Nephrol. 2003; 18:1260-1264. [PubMed: 14586677]

5. Groothoff JW, Offringa M, Van Eck-Smit BL, Gruppen MP, Van De Kar NJ, Wolff ED, Lilien MR, Davin JC, Heymans HS, Dekker FW. Severe bone disease and low bone mineral density after juvenile renal failure. Kidney Int. 2003; 63:266-275. [PubMed: 12472792]

6. Bartosh SM, Leverson G, Robillard D, Sollinger HW. Long-term outcomes in pediatric renal transplant recipients who survive into adulthood. Transplantation. 2003; 76:1195-1200. [PubMed: 14578753]

7. Bakkaloglu SA, Wesseling-Perry K, Pereira RC, Gales B, Wang HJ, Elashoff RM, Salusky IB. Value of the new bone classification system in pediatric renal osteodystrophy. Clin J Am Soc Nephrol. 2010; 5:1860-1866. [PubMed: 20634327]

8. National Kidney F. K/DOQI clinical practice guidelines for bone metabolism and disease in children with chronic kidney disease. Am J Kidney Dis. 2005; 46:S1-S121.

9. Bianchi ML, Baim S, Bishop NJ, Gordon CM, Hans DB, Langman CB, Leonard MB, Kalkwarf HJ. Official positions of the International Society for Clinical Densitometry (ISCD) on DXA evaluation in children and adolescents. Pediatr Nephrol. 2010; 25:37-47. [PubMed: 19603190]

10. Gutierrez O, Isakova T, Rhee E, Shah A, Holmes J, Collerone G, Juppner H, Wolf M. Fibroblast growth factor-23 mitigates hyperphosphatemia but accentuates calcitriol deficiency in chronic kidney disease. J Am Soc Nephrol. 2005; 16:2205-2215. [PubMed: 15917335]

11. Shimada T, Hasegawa H, Yamazaki Y, Muto T, Hino R, Takeuchi Y, Fujita T, Nakahara K, Fukumoto S, Yamashita T. FGF-23 is a potent regulator of vitamin D metabolism and phosphate homeostasis. J Bone Miner Res. 2004; 19:429-435. [PubMed: 15040831]

12. Shimada T, Kakitani M, Yamazaki Y, Hasegawa H, Takeuchi Y, Fujita T, Fukumoto S, Tomizuka K, Yamashita T. Targeted ablation of FGF23 demonstrates an essential physiological role of FGF23 in phosphate and vitamin D metabolism. J Clin Invest. 2004; 113:561-568. [PubMed: 14966565]

13. Larsson T, Nisbeth U, Ljunggren O, Juppner H, Jonsson KB. Circulating concentration of FGF-23 increases as renal function declines in patients with chronic kidney disease, but does not change in response to variation in phosphate intake in healthy volunteers. Kidney Int. 2003; 64:2272-2279. [PubMed: 14633152]

14. Ben-Dov IZ, Galitzer H, Lavi-Moshayoff V, Goetz R, Kuro O, Mohammadi M, Sirkis R, NavehMany T, Silver J. The parathyroid is a target organ for FGF23 in rats. J Clin Invest. 2007;

117:4003-4008. [PubMed: 17992255] 
15. Krajisnik T, Bjorklund P, Marsell R, Ljunggren O, Akerstrom G, Jonsson KB, Westin G, Larsson TE. Fibroblast growth factor-23 regulates parathyroid hormone and 1alpha-hydroxylase expression in cultured bovine parathyroid cells. J Endocrinol. 2007; 195:125-131. [PubMed: 17911404]

16. Isakova T, Wahl P, Vargas GS, Gutierrez OM, Scialla J, Xie H, Appleby D, Nessel L, Bellovich K, Chen J, Hamm L, Gadegbeku C, Horwitz E, Townsend RR, Anderson CA, Lash JP, Hsu CY, Leonard MB, Wolf M. Fibroblast growth factor 23 is elevated before parathyroid hormone and phosphate in chronic kidney disease. Kidney Int. 2011; 79:1370-1378. [PubMed: 21389978]

17. Bacchetta J, Dubourg L, Harambat J, Ranchin B, Abou-Jaoude P, Arnaud S, Carlier MC, Richard $\mathrm{M}$, Cochat $\mathrm{P}$. The influence of glomerular filtration rate and age on fibroblast growth factor 23 serum levels in pediatric chronic kidney disease. J Clin Endocrinol Metab. 2010; 95:1741-1748. [PubMed: 20157196]

18. Sinha MD, Turner C, Dalton RN, Rasmussen P, Waller S, Booth CJ, Goldsmith DJ. Investigating FGF-23 concentrations and its relationship with declining renal function in paediatric patients with pre-dialysis CKD Stages 3-5. Nephrol Dial Transplant. 201210.1093/ndt/gfs109

19. van Husen M, Fischer AK, Lehnhardt A, Klaassen I, Moller K, Muller-Wiefel DE, Kemper MJ. Fibroblast growth factor 23 and bone metabolism in children with chronic kidney disease. Kidney Int. 2010; 78:200-206. [PubMed: 20407479]

20. Siomou E, Challa A, Printza N, Giapros V, Petropoulou F, Mitsioni A, Papachristou F, Stefanidis CJ. Serum osteoprotegerin, RANKL and fibroblast growth factor-23 in children with chronic kidney disease. Pediatr Nephrol. 2011; 26:1105-1114. [PubMed: 21479768]

21. Wesseling-Perry K, Pereira RC, Tseng CH, Elashoff R, Zaritsky JJ, Yadin O, Sahney S, Gales B, Juppner H, Salusky IB. Early skeletal and biochemical alterations in pediatric chronic kidney disease. Clin J Am Soc Nephrol. 2012; 7:146-152. [PubMed: 22052943]

22. Levin A, Bakris GL, Molitch M, Smulders M, Tian J, Williams LA, Andress DL. Prevalence of abnormal serum vitamin D, PTH, calcium, and phosphorus in patients with chronic kidney disease: results of the study to evaluate early kidney disease. Kidney Int. 2007; 71:31-38. [PubMed: 17091124]

23. Lee K, Deeds JD, Bond AT, Juppner H, Abou-Samra AB, Segre GV. In situ localization of PTH/ PTHrP receptor mRNA in the bone of fetal and young rats. Bone. 1993; 14:341-345. [PubMed: 8395866]

24. Mathias R, Salusky I, Harman W, Paredes A, Emans J, Segre G, Goodman W. Renal bone disease in pediatric and young adult patients on hemodialysis in a children's hospital. J Am Soc Nephrol. 1993; 3:1938-1946. [PubMed: 8338926]

25. Wesseling-Perry K, Harkins GC, Wang H, Elashoff RM, Gales B, Horwitz MJ, Stewart AF, Juppner H, Salusky IB. The calcemic response to continous PTH(1-34) infusion in end-stage kidney disease varies according to bone turnover: a potential role for PTH(7-84). J Clin Endocrinol Metab. 2010; 95:2772-2780. [PubMed: 20382692]

26. Slatopolsky E, Finch J, Clay P, Martin D, Sicard G, Singer G, Gao P, Cantor T, Dusso A. A novel mechanism for skeletal resistance in uremia. Kidney Int. 2000; 58:753-761. [PubMed: 10916099]

27. Divieti P, John MR, Juppner H, Bringhurst FR. Human PTH-(7-84) inhibits bone resorption in vitro via actions independent of the type 1 PTH/PTHrP receptor. Endocrinology. 2002; 143:171176. [PubMed: 11751606]

28. D’Amour P, Brossard JH, Rousseau L, Nguyen-Yamamoto L, Nassif E, Lazure C, Gauthier D, Lavigne JR, Zahradnik RJ. Structure of non-(1-84) PTH fragments secreted by parathyroid glands in primary and secondary hyperparathyroidism. Kidney Int. 2005; 68:998-1007. [PubMed: 16105030]

29. Langub MC, Monier-Faugere MC, Wang G, Williams JP, Koszewski NJ, Malluche HH. Administration of PTH-(7-84) antagonizes the effects of PTH-(1-84) on bone in rats with moderate renal failure. Endocrinology. 2003; 144:1135-1138. [PubMed: 12639892]

30. Brossard JH, Cloutier M, Roy L, Lepage R, Gascon-Barre M, D'Amour P. Accumulation of a non(1-84) molecular form of parathyroid hormone (PTH) detected by intact PTH assay in renal failure: importance in the interpretation of PTH values. J Clin Endocrinol Metab. 1996; 81:39233929. [PubMed: 8923839] 
31. Brossard JH, Yamamoto LN, D’Amour P. Parathyroid hormone metabolites in renal failure: bioactivity and clinical implications. Semin Dial. 2002; 15:196-201. [PubMed: 12100458]

32. Lepage R, Roy L, Brossard JH, Rousseau L, Dorais C, Lazure C, D'Amour P. A non-(1-84) circulating parathyroid hormone $(\mathrm{PTH})$ fragment interferes significantly with intact PTH commercial assay measurements in uremic samples. Clin Chem. 1998; 44:805-809. [PubMed: 9554492]

33. Gao P, Scheibel S, D’Amour P, John MR, Rao SD, Schmidt-Gayk H, Cantor TL. Development of a novel immunoradiometric assay exclusively for biologically active whole parathyroid hormone 1-84: implications for improvement of accurate assessment of parathyroid function. J Bone Miner Res. 2001; 16:605-614. [PubMed: 11315988]

34. Monier-Faugere MC, Geng Z, Mawad H, Friedler RM, Gao P, Cantor TL, Malluche HH. Improved assessment of bone turnover by the PTH-(1-84)/large C-PTH fragments ratio in ESRD patients. Kidney Int. 2001; 60:1460-1468. [PubMed: 11576360]

35. Coen G, Bonucci E, Ballanti P, Balducci A, Calabria S, Nicolai GA, Fischer MS, Lifrieri F, Manni M, Morosetti M, Moscaritolo E, Sardella D. PTH 1-84 and PTH "7-84" in the noninvasive diagnosis of renal bone disease. Am J Kidney Dis. 2002; 40:348-354. [PubMed: 12148108]

36. Salusky IB, Goodman WG, Kuizon BD, Lavigne JR, Zahranik RJ, Gales B, Wang HJ, Elashoff RM, Juppner H. Similar predictive value of bone turnover using first- and second-generation immunometric PTH assays in pediatric patients treated with peritoneal dialysis. Kidney Int. 2003; 63:1801-1808. [PubMed: 12675856]

37. Joly D, Drueke TB, Alberti C, Houillier P, Lawson-Body E, Martin KJ, Massart C, Moe SM, Monge M, Souberbielle JC. Variation in serum and plasma PTH levels in second-generation assays in hemodialysis patients: a cross-sectional study. Am J Kidney Dis. 2008; 51:987-995. [PubMed: 18430500]

38. Klaus G, Watson A, Edefonti A, Fischbach M, Ronnholm K, Schaefer F, Simkova E, Stefanidis CJ, Strazdins V, Vande Walle J, Schroder C, Zurowska A, Ekim M. Prevention and treatment of renal osteodystrophy in children on chronic renal failure: European guidelines. Pediatr Nephrol. 2006; 21:151-159. [PubMed: 16247644]

39. Wesseling-Perry K, Pereira RC, Sahney S, Gales B, Wang HJ, Elashoff R, Juppner H, Salusky IB. Calcitriol and doxercalciferol are equivalent in controlling bone turnover, suppressing parathyroid hormone, and increasing fibroblast growth factor-23 in secondary hyperparathyroidism. Kidney Int. 2011; 79:112-119. [PubMed: 20861820]

40. Pereira RC, Juppner H, Azucena-Serrano CE, Yadin O, Salusky IB, Wesseling-Perry K. Patterns of FGF-23, DMP1, and MEPE expression in patients with chronic kidney disease. Bone. 2009; 45:1161-1168. [PubMed: 19679205]

41. Sabbagh Y, Graciolli FG, O’Brien S, Tang W, Dos Reis LM, Ryan S, Phillips L, Boulanger J, Song W, Bracken C, Liu S, Ledbetter S, Dechow P, Canziani ME, Carvalho AB, Jorgetti V, Moyses RM, Schiavi SC. Repression of osteocyte Wnt/beta-catenin signaling is an early event in the progression of renal osteodystrophy. J Bone Miner Res. 2012; 27:1757-1772. [PubMed: 22492547]

42. Salusky IB, Brill J, Oppenheim W, Goodman WG. Features of renal osteodystrophy in pediatric patients receiving regular peritoneal dialysis. Semin Nephrol. 1989; 9:37-42. [PubMed: 2740652]

43. Wesseling-Perry K, Pereira RC, Wang H, Elashoff RM, Sahney S, Gales B, Juppner H, Salusky IB. Relationship between plasma FGF-23 concentration and bone mineralization in children with renal failure on peritoneal dialysis. J Clin Endocrinol Metab. 2009; 94:511-517. [PubMed: 19050056]

44. Lieben L, Masuyama R, Torrekens S, Van Looveren R, Schrooten J, Baatsen P, Lafage-Proust MH, Dresselaers T, Feng JQ, Bonewald LF, Meyer MB, Pike JW, Bouillon R, Carmeliet G. Normocalcemia is maintained in mice under conditions of calcium malabsorption by vitamin Dinduced inhibition of bone mineralization. J Clin Invest. 2012; 122:1803-1815. [PubMed: 22523068]

45. Langman CB, Mazur AT, Baron R, Norman ME. 25-hydroxyvitamin D3 (calcifediol) therapy of juvenile renal osteodystrophy: beneficial effect on linear growth velocity. J Pediatr. 1982; 100:815-820. [PubMed: 7069549] 
46. Lund RJ, Davies MR, Brown AJ, Hruska KA. Successful treatment of an adynamic bone disorder with bone morphogenetic protein-7 in a renal ablation model. J Am Soc Nephrol. 2004; 15:359_ 369. [PubMed: 14747382]

47. Rhee Y, Bivi N, Farrow E, Lezcano V, Plotkin LI, White KE, Bellido T. Parathyroid hormone receptor signaling in osteocytes increases the expression of fibroblast growth factor-23 in vitro and in vivo. Bone. 2011; 49:636-643. [PubMed: 21726676]

48. Liu S, Zhou J, Tang W, Menard R, Feng JQ, Quarles LD. Pathogenic role of Fgf23 in Dmp1-null mice. Am J Physiol Endocrinol Metab. 2008; 295:E254-E261. [PubMed: 18559986]

49. Lorenz-Depiereux B, Schnabel D, Tiosano D, Hausler G, Strom TM. Loss-of-function ENPP1 mutations cause both generalized arterial calcification of infancy and autosomal-recessive hypophosphatemic rickets. Am J Hum Genet. 2010; 86:267-272. [PubMed: 20137773]

50. Mackenzie NC, Zhu D, Milne EM, van 't Hof R, Martin A, Quarles DL, Millan JL, Farquharson C, MacRae VE. Altered bone development and an increase in FGF-23 expression in Enpp 1(-/-) mice. PLoS One. 2012; 7:e32177. [PubMed: 22359666]

51. Parker BD, Schurgers LJ, Brandenburg VM, Christenson RH, Vermeer C, Ketteler M, Shlipak MG, Whooley MA, Ix JH. The associations of fibroblast growth factor 23 and uncarboxylated matrix Gla protein with mortality in coronary artery disease: the Heart and Soul Study. Ann Intern Med. 2010; 152:640-648. [PubMed: 20479029]

52. Gutierrez OM, Mannstadt M, Isakova T, Rauh-Hain JA, Tamez H, Shah A, Smith K, Lee H, Thadhani R, Juppner H, Wolf M. Fibroblast growth factor 23 and mortality among patients undergoing hemodialysis. N Engl J Med. 2008; 359:584-592. [PubMed: 18687639]

53. Isakova T, Xie H, Yang W, Xie D, Anderson AH, Scialla J, Wahl P, Gutierrez OM, Steigerwalt S, He J, Schwartz S, Lo J, Ojo A, Sondheimer J, Hsu CY, Lash J, Leonard M, Kusek JW, Feldman HI, Wolf M. Fibroblast growth factor 23 and risks of mortality and end-stage renal disease in patients with chronic kidney disease. JAMA. 2011; 305:2432-2439. [PubMed: 21673295]

54. Oliveira RB, Cancela AL, Graciolli FG, dos Reis LM, Draibe SA, Cuppari L, Carvalho AB, Jorgetti V, Canziani ME, Moyses RM. Early control of PTH and FGF23 in normophosphatemic CKD patients: a new target in CKD-MBD therapy? Clin J Am Soc Nephrol. 2010; 5:286-291. [PubMed: 19965540]

55. Gonzalez-Parra E, Gonzalez-Casaus ML, Galan A, Martinez-Calero A, Navas V, Rodriguez M, Ortiz A. Lanthanum carbonate reduces FGF23 in chronic kidney disease stage 3 patients. Nephrol Dial Transplant. 2011; 26:2567-2571. [PubMed: 21436379]

56. Shimada T, Yamazaki Y, Takahashi M, Hasegawa H, Urakawa I, Oshima T, Ono K, Kakitani M, Tomizuka K, Fujita T, Fukumoto S, Yamashita T. Vitamin D receptor-independent FGF23 actions in regulating phosphate and vitamin D metabolism. Am J Physiol Renal Physiol. 2005; 289:F1088-F1095. [PubMed: 15998839]

57. Teng M, Wolf M, Lowrie E, Ofsthun N, Lazarus JM, Thadhani R. Survival of patients undergoing hemodialysis with paricalcitol or calcitriol therapy. N Engl J Med. 2003; 349:446-456. [PubMed: 12890843]

58. Teng M, Wolf M, Ofsthun MN, Lazarus JM, Hernan MA, Camargo CA Jr, Thadhani R. Activated injectable vitamin D and hemodialysis survival: a historical cohort study. J Am Soc Nephrol. 2005; 16:1115-1125. [PubMed: 15728786]

59. Wolf M, Molnar MZ, Amaral AP, Czira ME, Rudas A, Ujszaszi A, Kiss I, Rosivall L, Kosa J, Lakatos P, Kovesdy CP, Mucsi I. Elevated fibroblast growth factor 23 is a risk factor for kidney transplant loss and mortality. J Am Soc Nephrol. 2011; 22:956-966. [PubMed: 21436289] 
a

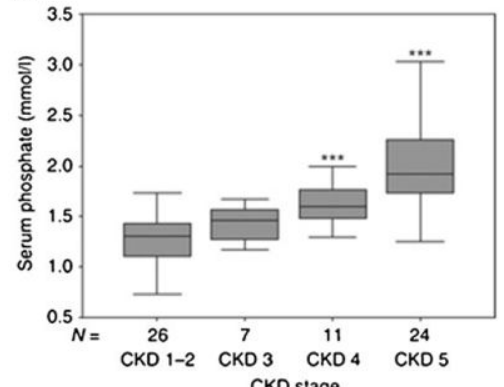

b

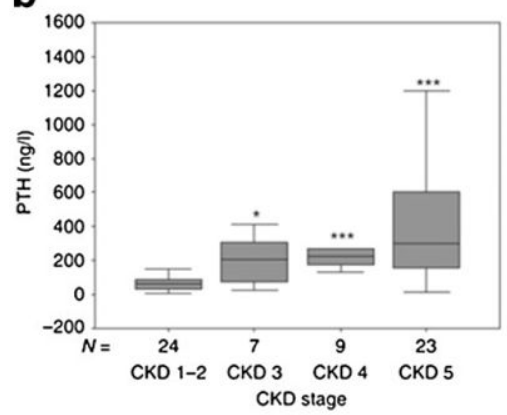

C

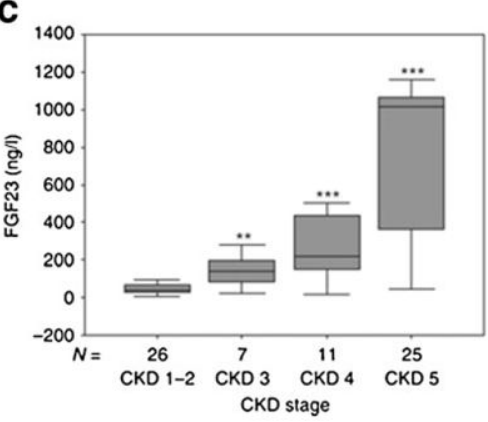

Fig. 1.

Serum values of phosphate (a), parathyroid hormone $(P T H)(\mathbf{b})$, and fibroblast growth factor 23 (FGF23) (c) in a cross-section of pediatric patients with pre-dialysis chronic kidney disease $(C K D)$. $* P<0.01 \mathrm{CKD}$ stage $1-2$ vs. CKD stage $3, * * * P<0.001 \mathrm{CKD}$ stage $1-2$ vs. CKD stage $4, * * * P<0.001$ CKD stage $1-2$ vs. CKD stage 5. Boxes and bars Interquartile range and median value, respectively, whiskers distance to the smallest and largest unbooked sample value. Reprinted with permission (van Husen et al. Kidney Int 2010; 78:200-206 [19]) 


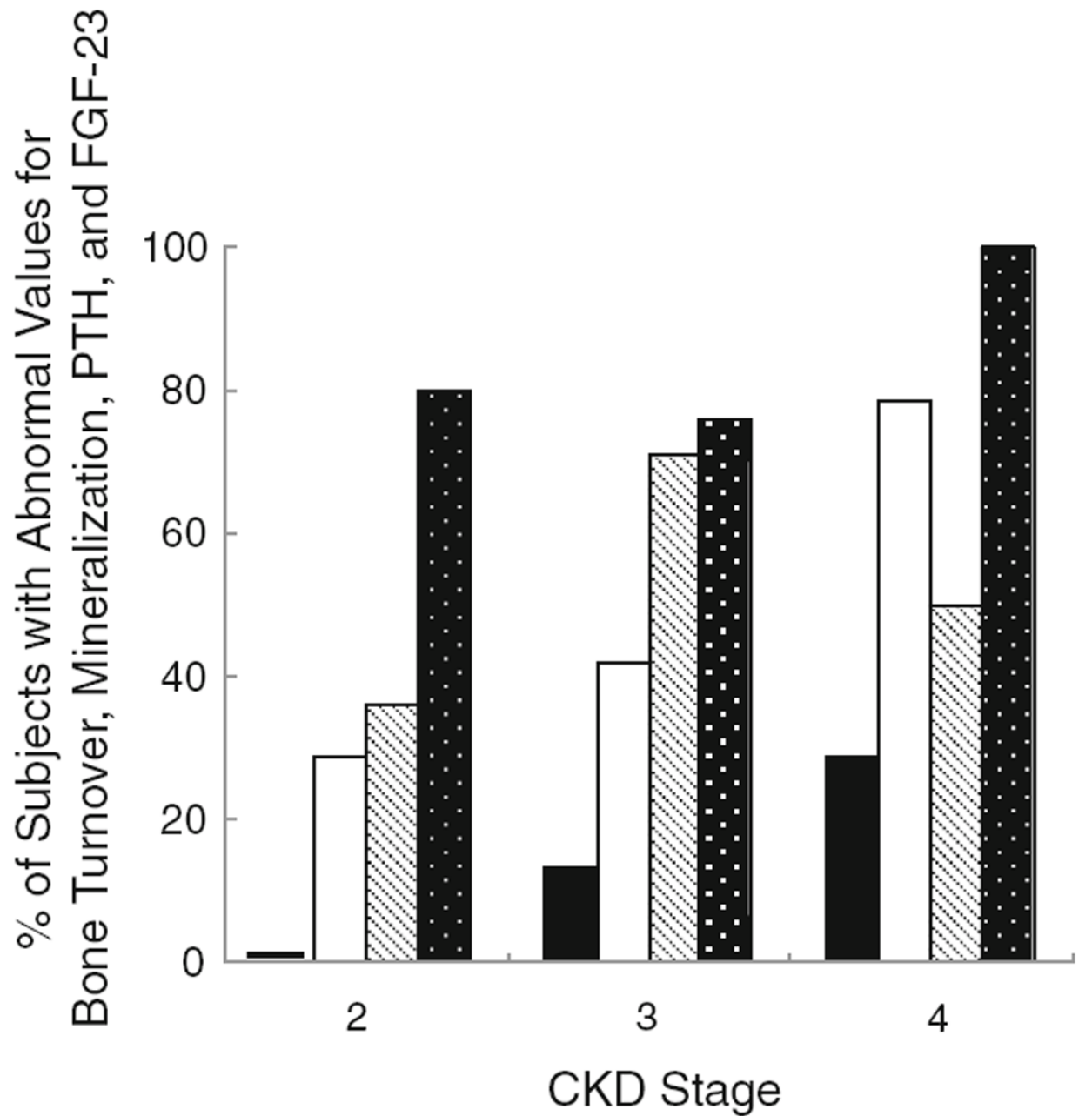

Fig. 2.

Prevalence of increased rates of bone formation rate (black bar), mineralization defect (white bar), increased parathyroid hormone (PTH) levels (striped bar), and increased FGF 23 values (black polka-dotted bar) in pediatric patients with Chronic Kidney disease (CKD). The mineralization defect was defined as an abnormal accumulation of osteoid (osteoid volume) in combination with a delay osteoid maturation time. Increased PTH values were defined as values above the range currently recommended by the Kidney Disease Outcomes Quality Initiative for CKD in children. Increased FGF23 values were defined as values above the range determined in healthy children. Reprinted with permission (Wesseling-Perry et al. Clin J Am Soc Nephrol. 2012; 7:146-52 [21]) 

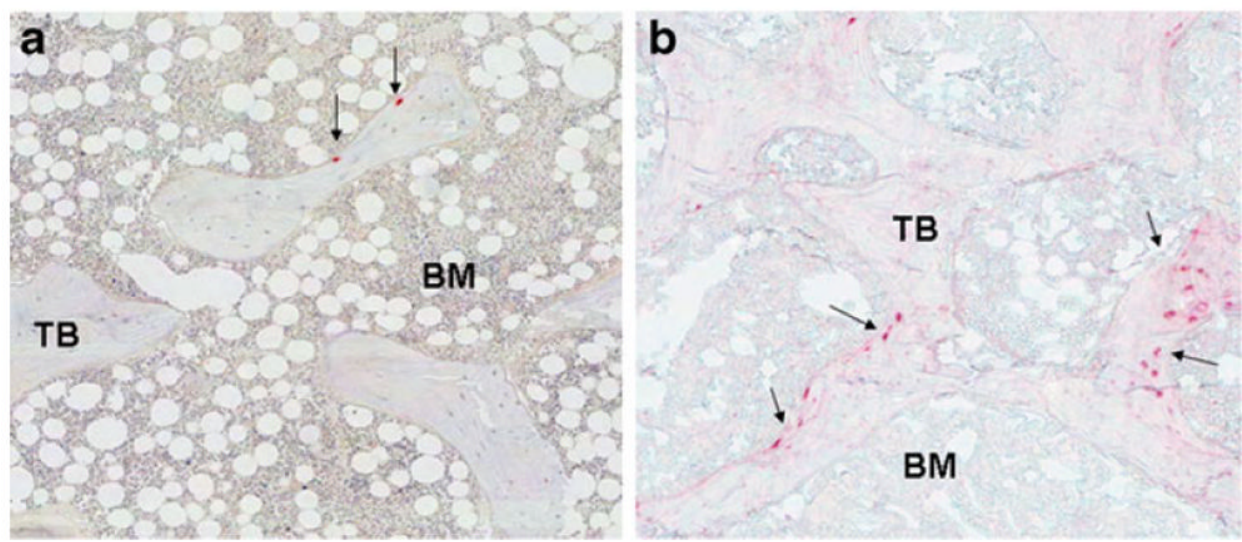

Fig. 3.

Fibroblast growth factor 23 (FGF23) expression (arrows) is markedly increased in patients with early (stage 2) Chronic Kidney disease (CKD) (b) as compared to control (a). BM Bone marrow, $T B$ trabecular bone. Arrows indicate osteocytes with positive staining for FGF 23. Reprinted with permission (Pereira RC et al. Bone 2009; 45:1161-1168 [40]) 


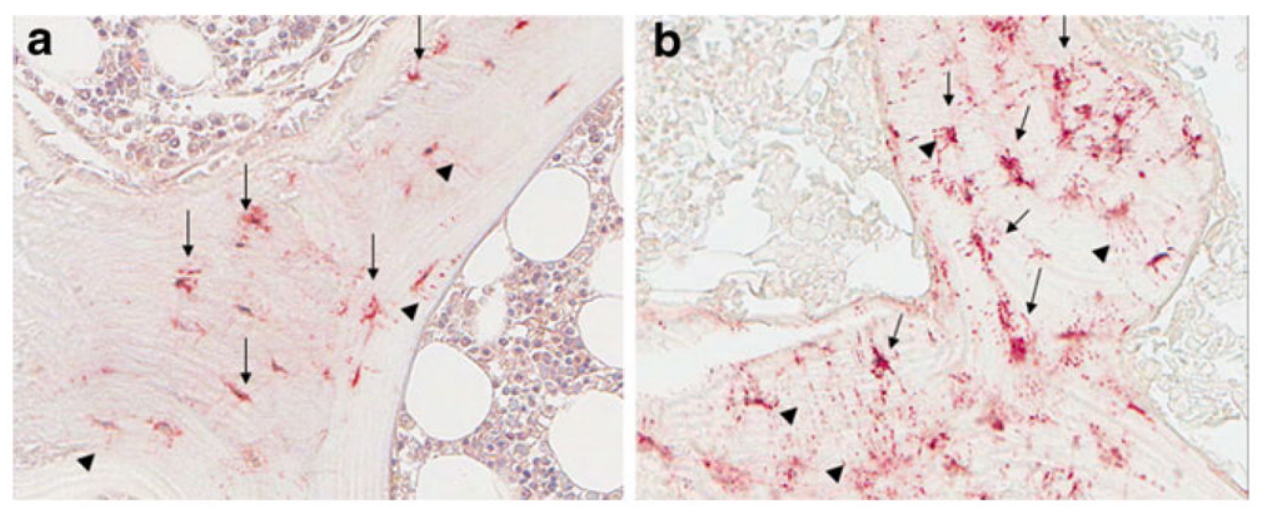

Fig. 4.

Dentin matrix protein 1 (DMP1) expression is markedly increased in patients with early (stage 2) CKD (b) as compared to control (a). Arrows indicate osteocytes with positive staining for DMP1. Reprinted with permission (Pereira RC et al. Bone 2009; 45:1161-1168 [40]) 